\title{
Büyükbaş Hayvancılıkta Kayıt Tutma Sistemine Yönelik Bir Bilgisayar Paket Programının Hazırlanması
}

\section{Hasan ÇELİKYÜREK ${ }^{1 *}$}

\author{
${ }^{1}$ Van Yüzüncü Yıl Üniversitesi, Gevaş Meslek Yüksekokulu, Van, Türkiye \\ ${ }^{2}$ Van Yüzüncü Y1l Üniversitesi, Ziraat Fakültesi, Zootekni Bölümü, Van, Türkiye \\ * e-posta: hasancy@yyu.edu.tr, Tel: +90 (432) 612 2434, Faks: +90 (432) 6122435
}

Özet: Bu çalışmada, büyükbaş hayvanlara ait bilgilerin kaydedilmesine yönelik bir bilgisayar paket programı hazırlanmıştır. Bu program, büyükbaş hayvanların ıslah çalışmalarında sığırlar için 581 adet farklı veriyi kaydedebilecek bir programdır. Program Visual Basic ile yazılmıştır. Veritabanı olarak Microsoft Access dosyaları kullanılmıştır. Raporlama işlemleri için Microsoft Excel programı kullanılmıştır. Hazırlanan bilgisayar paket programında tutulan kayıtlar genel olarak islah, bakım, besleme, yem, kesim öncesi ve sonrası veriler, hastalık, sürü yönetimi, soy kütüğü vb. kayıtlardır. Bu çalışmada hazırlanan paket program sayesinde küçük ve orta ölçekli işletmelerde büyükbaş hayvanlarda tutulan kayıtlar bilgisayar ortamına aktarılarak veritabanlarında uzun süre saklanabilmekte ve ihtiyaç anında istenen verilere hızlı bir şekilde ulaşılabilmektedir. Hayvan ıslahı çalışmalarının ilk ve en önemli aşamalarından biri olan verim kayıtlarının tutulmasıdır. Bu amaçla hazırlanan bu tür bilgisayar paket programları kullanılarak hayvancılıkta önemli bir yere sahip her türlü verim kaydı kayıt altına alınabilmektedir.

Anahtar kelimeler: Bilgisayar paket programı, Kayıt tutma, Sığır, Veritabanı

\section{Preparation of a Computer Package Program for the Recording System in Cattle and Buffalo Husbandry}

\begin{abstract}
In this study, a computer packet program for recording the information on the small ruminants was prepared. This program is a program that can save the 581 different pieces of data for cattle in the works of the animal breeding work of small ruminants. The program was written in Visual Basic. The files of Microsoft Access were used as a database. Microsoft Excel was used for the reporting processes. In general, records kept in the computer software package are the breeding, the care, the feeding, the feed, the data before and after slaughtering, the illness, the herd management, the pedigree and so on. Through this study, by transferred to computer the records of small ruminants in the small and the medium-sized firms can be stored in databases for a long time. Also, when needed, the desired data can be reached quickly. It is one of the first and the most important stages of animal breeding studies to keep the yield records. Using this kind of computer package programs prepared for this purpose, the efficiency recording having an important place in animal husbandry can be recorded.
\end{abstract}

Keywords: Cattle, Computer software program, Database, Recording

\section{Giriş}

Hayvancılık, bütün dünyada olduğu gibi Türkiye'de de artan nüfusun yeterli ve dengeli beslenmesinde ve birçok alanda endüstri hammaddesi olarak kullanılması açısından önemli bir yer tutmaktadır (Gaytancıŏlu 2008). Modern yetiştiricilik sistemleri ve dünya hayvancıllğına entegrasyonunun sağlanması açısından çağdaş hayvan yetiştiriciliğinde işletme ölçeğinin büyüklüğüne göre farklı şekillerde kayıt tutulması zorunluluk haline gelmiştir. Son yıllardaki teknolojik gelişmeler kayıt tutmada bilgisayar kullanım oranını bir hayli artırmıştır (Gökçen 2015). Ancak, Türkiye'de bilişim teknolojilerinin yaygınlaşması ve kullanımı istenen düzeyde değildir (Dolgun ve ark. 2009). Gelişmiş ülkelerde bu kayıtlar sağlıklı bir şekilde veritabanlarında saklanmaktadır (FAO 2014). Veritabanları sayesinde veriler uzun süre saklanabilmekte, istenen verilere hızlı bir şekilde ulaşılabilmekte, geçmişteki uygulamaların neden-sonuç ilişkisinden yola çıkarak bu veriler ile daha sistemli, kararlı ve hatasız adımlar atılabilmektedir. Yerli yazılımların geliştirilmesine destek verilmesi ülke hayvancılığı açısından çok 


\section{H. ÇELİKYÜREK, T. AYGÜN}

önemlidir. Böylece yurtdışından yazılım ithalatı azaltılarak ülke ekonomisine önemli bir katkı sağlanmış olur. Hazırlanacak yazılım programları teknolojik yeniliklere ve yasal düzenlemelere açık olmalıdır. Programlar mevcut şartlara göre sürekli yenilenip geliştirilebilmelidir (Aydın ve Günlü 2010). Paket programlar, temel konularda yetiştiriciyi ya da araştırmacıyı bilgilendirecek ve damızlık hayvan seçimini kolay bir şekilde yapabilecek bilgiyi de vermelidir. Modern hayvancılık işletmelerinde kullanılacak bilgisayar paket programları tüm araştırmacı ve yetiştiricilerin görüş ve talepleri ile birlikte Türkiye'nin hayvancılık karakteristikleri de dikkate alınarak hazırlanmalıdır. Islah ve melezleme çalışmalarında öncelik; mevcut materyal ve durumun kayıt altına alınmasıdır.

\section{Materyal ve Yöntem}

$\mathrm{Bu}$ programın hazırlanmasında Intel ${ }^{\circledR}$ Core ${ }^{\mathrm{TM}}$ i7-4500U $1.80 \mathrm{GHz}$ işlemciye sahip, 256 GB disk kapasiteli, 8 GB RAM belleğe sahip bir bilgisayar kullanılmıştır. Bu bilgisayarda üç farklı bölüm (Partition) oluşturularak bilgisayara üç farklı işletim sistemi kurulmuştur. Bunlar; Microsoft Windows XP Proffesional, Microsoft Windows 7 Proffesional ve Microsoft Windows 8 Proffesional işletim sistemleridir Üç farklı işletim sisteminin kurulmasındaki amaç programın farklı işletim sistemlerindeki davranışı, testi ve uyumluluğunun yapılandırılmasıdır.

Küçükbaş ve Büyükbaş Sürü Yönetimi ve Kayıt Programının yazımında Microsoft firmasının tümleşik geliştirme ortamı (IDE) olan Microsoft Visual Studio yazılımının Microsoft Visual Basic Programlama dili kullanılmıştır. Programın son aşamasında Microsoft Visual Basic Programı araçlarından derleyici (Compiler) yardımıyla program exe'ye dönüştürülmüsştür. Programın derlenip dağıtılması için yine Visual Basic'te bulunan Paket ve Dağıtım Sihirbazı (Package and Deployment Wizard) ile program paketlenerek dağıtım için hazır hale getirilmiştir. Verilerin kaydedilmesi ve saklanmasında yine Microsoft firmasının geliştirmiş olduğu Microsoft Access programı, raporlamada Microsoft Excel ve Microsoft Word programları kullanılmıştır. Resimlerin yapılması ve düzenlenmesinde Adobe firmasının geliştirmiş olduğu Adobe PhotoShop programı; program simgelerinin oluşturulmasında Aha-Soft firmasının Any to Icon programı kullanılmıştır. Programdaki simgelerin kimisi Adobe PhotoShop programı kullanılarak bilgisayar ortamında tasarlanmış kimisi de internet ortamında ücretsiz olarak indirmeye müsaade edilen sitelerden indirilmiştir.

\section{Bulgular}

\section{A - Veri Giriş Formları}

\section{Programa Giriş ve Ana Form Ekranı}

Program çalıştıııldığında şifreli giriş ekranı ile karşılaşılacaktır. Bu ekranda kullanıcı adı ve şifre bilgileri doğru olarak girildikten sonra Ana Form ekrana gelecektir (Şekil 1).

\section{Hayvan Tanimlama Formu}

Büyükbaş hayvan tanımlama ve veritabanına kayıt işleminin yapıldı̆̆ı formdur. "Hayvan Tanımlama" komut düğmesi ya da "Hayvan Kayıtları" menüsü açıldıktan sonra ulaşılan ekrandır. Formda girilecek verilerin tespitinde Özhan ve ark. (2011)' 1 n bildirdiklerinden faydalanılmıştır. Hayvan Tanımlama Form aracılığıyla büyükbaş hayvanlarda tüm tanımlayıcı kayıtlar veritabanına kaydedebilmektedir. Programın hızlı ve seri kullanılabilmesi için kısayol tuşları, veri girişlerinde süzgeçler ve hızlı tuş atamaları yapılmıştır.

\section{3. Çiftleşme / Aşım Kayıtları ve Aşıı İstatistikleri Formu}

Form aracılığı ile aşım ve buzağılama sonuçlarına göre döl verimi ölçütleri hesaplanmaktadır. Yine form aracılığıyla aşım, gebelik ve doğum hatıllatmaları da yapılabilmektedir. Oranların hesaplanması ve sayıların tespitinde; Kumlu (1999a; 1999b), Kulaksız ve ark. (2011) ve Kaymakçı (2013)'nın belirtmiş oldukları eşitlikler temel alınmıştır. 


\section{Günlük ve Laktasyon Süt Kayltları ile Süt Verimi Hesaplama Formu}

Günlük, aylık, yıllık veya belirlenen denetimler aralığındaki süt verimi kayıtlarının tutulduğu formdur. Süt verimleri girildikçe günlük ve laktasyondaki toplam süt, laktasyon ortalama, en yüksek ve kısmı süt verimlerini hesaplayarak ilgili metin kutularına yazmaktadır. Elde edilen bilgiler ışığında süt verimi hesaplamaları ise; İsveç, Vogelin, Hollanda, Trapez I, Trapez II (Fleischmann) yöntemlerine göre yapılmaktadır. Kullanılan eşitlikler Şahin ve Akmaz. (2004), Turan (2004), Ceyhan ve ark. (2007), Ertuğrul ve ark. (2011), Karaca ve ark. (2012), Yakan (2012) ile Kaymakçı (2013)'nın belirtmiş oldukları eşitlikler temel alınarak program tarafından hesaplatılmıştır.

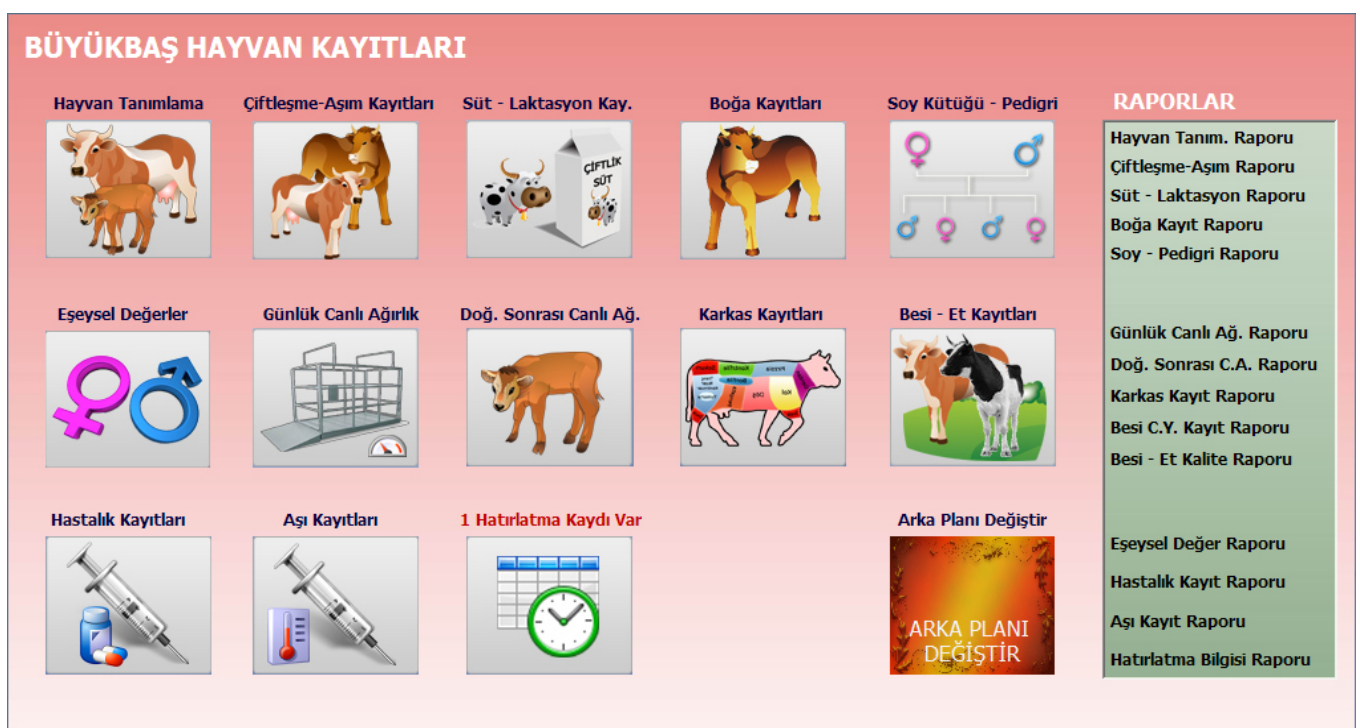

Şekil 1. Programın ana formu ve diğer formlara ulaşım butonları. Formlarda tutulan kayıt türlerinin tekrarından kaçınmak için sadece öne çıkan kayıt türlerine yer verilmiştir.

\section{Soy Kütüğ̈̈ - Pedigri Kayıtları Formu}

Bu form aracilığı hayvanların 4 nesil kadar pedigri / soy bilgileri tutulmaktadır. Tutulacak kayıtların belirlenmesinde Özhan ve ark. (2011), Kumlu (1999a; 1999b) ve Kaymakçı (2013)'nın belirtmiş olduğu özellikler temel alınmıştır. Genel olarak form aracılığıyla tutulan kayıtlar; hayvan tanımlama bilgilerinin yanı sıra, yıl bilgisi, süt, yağ, soy ağacındaki yeri gibi bilgilerden oluşmaktadır.

\section{Damızlık Boğa ve Gelişme Kayıtları Formu}

Form yardımıyla damızlık boğa kayıtları tutulmaktadır. Program boğaların birinci ve ikinci nesil annebaba kayıtlarını da tutmaktadır. Tutulacak kayıtların belirlenmesinde Kaymakçı ve Sönmez (1992), Kumlu (1999a; 1999b) ve Kaymakçı (2013)'nın belirtmiş olduğu özellikler temel alınmıştır. Bunlara ilave olarak gelişme kayıtları da tutulabilmektedir.

\section{Günlük Canlı Ağırlık Kayıtları Formu}

Form aracılığıyla büyükbaş hayvanlarda her gün için 3 tartım yapılabilmektedir. İsteğe bağlı olarak tek, iki ya da üç tartım yapılabilmektedir. Tartım sayısını arttırmak kullanıcının isteği doğrultusunda gerçekleşmektedir.

\section{Doğum Sonrası 180. Güne Kadar Canlı Ağırlık Kayıtları Formu}

Tutulacak kayıtların tespitinde çeşitli kaynaklardan elde edilen bilgiler doğrultusunda günlerin esnek olması şartıyla temel olarak; hayvanlarda doğum, sütten kesim, 30., 60., 90., 120., 150. ve 180. gün canlı ağırlıkları gibi kayıtlarının alındığı formdur. 


\section{H. ÇELİKYÜREK, T. AYGÜN}

\section{Karkas ve Vücut Ölçüleri ile İlgili Kayıt Formu}

Karkas ve Vücut ile ilgili özelliklere ait kayıtların tespitinde konu ile ilgili birçok makale değerlendirilerek kayıt türleri belirlenmiştir. Tutulacak veriler; Özhan ve ark. (2011), Kumlu (1999a; 1999b), Gökdal ve ark. (2003), Akdağ (2004), Cloete et al. (2004), McGee et al. (2007), Yaralı ve Karaca (2011), Öztürk ve Odabaşığlu (2011) ile Anonim (2016) makalelerinden faydalanılarak belirlenmiştir.

\subsection{Vücut ölçüleri ile ilgili kayıt sekmesi}

$\mathrm{Bu}$ kısımda hayvanların genel olarak vücut ölçüleri ile ilgili kayıtlar tutulmaktadır. Bu sekme ile tutulabilen kayıtlar vücut ölçüleri ile ilgili kayıtlardır. Cidago yüksekliği, vücut uzunluğu, sağrı genişliği, göğüs çevresi, but çevresi, vb. tutulan kayıtlardan sadece birkaçıdır.

\subsection{Kesim özellikleri ve oran hesaplamaları sekmesi}

Kesim özellikleri ve oran hesaplamaları sekmesi ile kesime ait kayı girişleri yapılmaktadır. Kesim özelliklerinin yazılması neticesinde hesaplanarak veritabanına kaydı yapılan oranlar; soğuk, sıcak karkas, baş, 4ayak, dalak, iç yağı, deri ve ciğer takımı oranlarıdır.

\subsection{Karkas ölçüleri ile ilgili kayıt sekmesi}

Karkas ölçüleri sekmesi ile karkasa ait ölçü kayıtları girişi yapılmaktadır. Burada; karkas uzunluğu, but çevresi, but uzunluğu, sağrı genişliği, göğüs genişliği, göğüs derinliği, kabuk yağı kalınlığı vb. kayıtları tutulmaktadir.

\subsection{Karkas özellikleri, pirzola fiziksel analizleri ve hesaplamaları}

Bu sekme aracılığıyla karkas özellikleri ile pirzolaya ait bileşenlerin kayıtları tutulmaktadır. Karkas ile pirzolaya ait oranlar, değerlerin girişi sonucu program tarafından otomatik olarak hesaplanmaktadır.

\section{Besi Bilgileri ve Et Kalitesi Kayıtları Formu}

Besi bilgileri ve et kalitesi kayıtları iki sekme aracılığıyla aynı ekranda gerçekleştirilmektedir.

\subsection{Besi ve yem bilgileri kayttlart ve hesaplamalar sekmesi}

$\mathrm{Bu}$ sekme ile hayvanların besiye alınması ve besi süresince denetimler arasında yapılan tartımlar ve sonuçları kaydedilmektedir. Eşitliklerin belirlenmesinde diğer çalışmalara ek olarak Güney ve Ocak (2010) ile Kaymakçı (2013)'nın bildirdiklerinden faydalanılmıştır. Form aracılığıyla besiye alınan ve denetimlerde elde edilen canlı ağırlık kayıtları ve verilen yeme ait tüm içerik kayıtları tutulabilmektedir.

\subsection{Et kalitesi ve özellikleri ile hesaplamaları sekmesi}

Form aracılığıla et kalite ve özelliklerine ait tüm kayıtlar tutulabilmektedir. Bu kısımdaki bilgilerden Pasif Su Kaybı, Chroma, Hue Angle, Pişirme Kaybı, Su Tutma Kapasitesi gibi bilgiler program tarafından hesaplanmaktadır. Eşitliklerin belirlenmesinde; Jones (1995), Insausti et al. (1999), GarcíaSegovia et al. (2007) ile Ekiz ve ark. (2012)'nın bildirdiklerinden faydalanılmıştır.

\section{Eşeysel Üreme Davranışları Kaylt Formu}

Form aracılığıyla eşeysel davranış ölçütleri veritabanına kaydedilmektedir. Tutulan kayıtlardan flehmen, ejekülasyonlar arası süre, paralel yanaşma, toslama, biniş yaşı, biniş ağırlığı bunlardan sadece birkaçıdır. Kaydı tutulan kriterlerin belirlenmesinde diğer çalışmalara ek olarak Alpan (1993), Kumlu (1999b), Kaymakçı (2013)'nın bildirdiklerinden faydalanılmıştır. 


\section{Hastallk Kayttlart ve Hastallk Bilgileri Kaylt Formu}

Programda hayvanların en sık karşılaştıkları hastalıklara ait hazır bir veritabanı mevcuttur. Ayrıca yeni hastalık kayıtları da yapılabilmektedir. Veritabanında hastalığın ismi, hastalık nedeni, belirtileri, tedavi / sağaltımı gibi bilgiler bulunmaktadır. Hastalıklar ve tutulması gereken kayıt tespiti için Aytuğ ve ark. (1989), Sekin ve ark. (1996), Özhan ve ark. (2011)'nın bildirdiklerinden faydalanılmıştır.

\section{Aşı Kayıtları ve Aşı Bilgileri Kayıt Formu}

Aşlar ile ilgili temel bilgileri veritabanında tutmaktadır. Ayrıca yeni aşılar ve bilgilerin eklenebileceği bir imkânı da sağlamaktadır. Aşının uygulamasından takibine kadar birçok veriyi kayıt altına alabilmektedir. Eklenen aşılar ve tutulması gereken kayıt tespiti Aytuğ ve ark. (1989), Aytekin ve ark. (2011), Altuğ ve ark. (2013), Anonim (2014)'in bildirdiklerinden faydalanılmıştır.

\section{Hattrlatma Bilgileri Kayıt Formu}

Daha önce girilmiş olan hatırlatma bilgileri bu ekran vasıtasıyla görülmektedir. Program kullanılırken veritabanına kaydedilen hatırlatma bilgi ve kayıtları şunlardan oluşmaktadır. 1- Aşı, 2- Aşım, 3- Doğum, 4- Gebelik, 5- Hastalık kayıtları şeklindedir. Hatırlatmaların ayırt edilebilmesi için her hatırlatma türü farklı bir renkte tasarlanmıştır.

\section{B - Verilerin Seçime Tabii Tutularak Yazdırılması}

Bu kısımdaki formlar (Şekil 2) girilen kayıtların dışarıya aktarılması işlemleri için kullanılmaktadır. Veriler Microsoft Excel programına aktarılırken hiyerarşik yapı korunarak ve kullanıcı istekleri gözönüne alınarak sadece istenen bilgiler aktarılmaktadır.

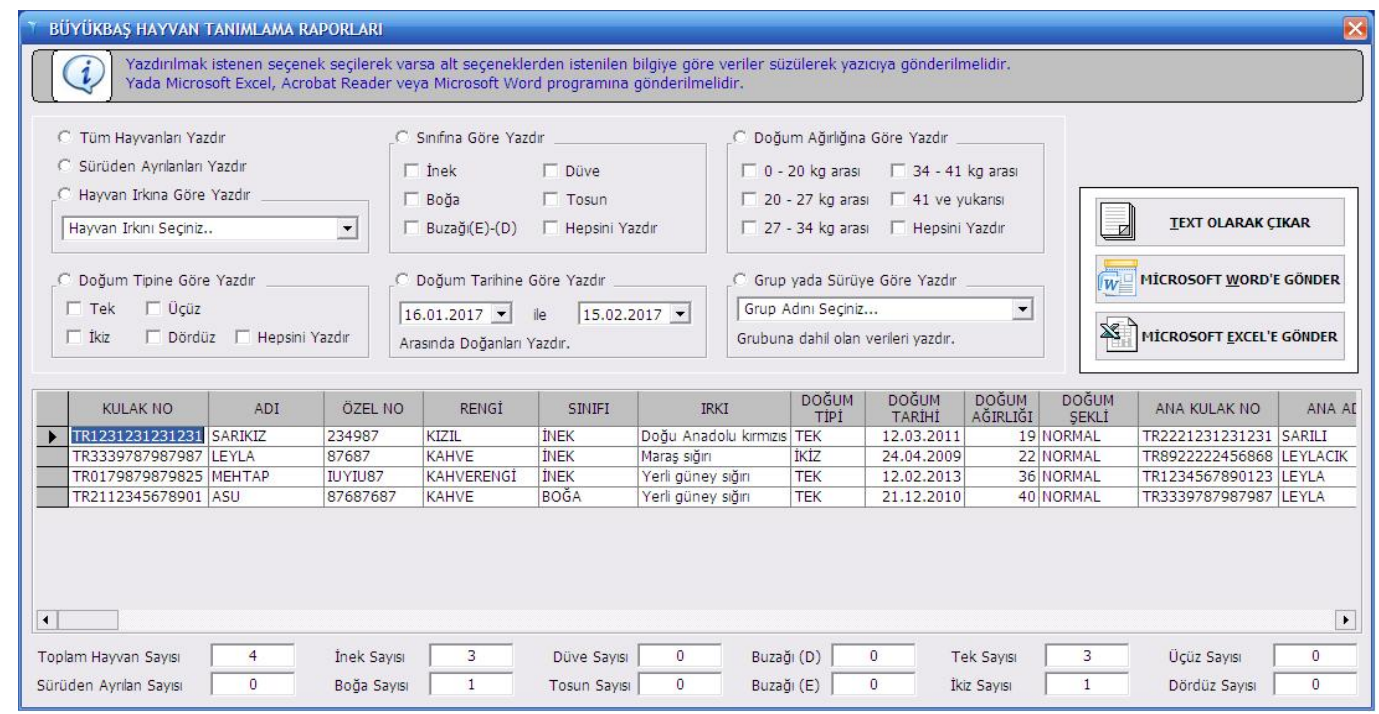

Şekil 2. Hayvan tanımlama kayıtları raporlama formu.

Yukarıda sıralanan tüm veri giriş formlarına ait raporlama formları da tasarlanmıştır. Her raporlama formu tutulan kayıtlar ve üzerinde durulan özelliklere göre önemli sayılabilecek belirleyici esaslara göre bir süzgeç düşünülerek tasarlanmıştır. Genel olarak formun kullanımı; istenen tekli seçim düğmelerinden seçim yapmak varsa alt seçenekleri içerisinden de istenen seçenekler seçilerek Microsoft Excel'e Gönder komut düğmesine tıklamak şeklindedir.

\section{Tartışma ve Sonuç}

Dünyada ve Türkiye'de önceki yıllarda hayvancılık kayıtlarının bilgisayar destekli olarak veritabanına işlenmesi konularında yapılan çalışmaların salt çoğunluğu kısıtlı bir veriyi veritabanında tutmaktadır (Çelikyürek ve Aygün 2014). Yazılımlar işletmeye özgü olarak tasarlanmış ve çoğunlukla tek ya da 


\section{H. ÇELİKYÜREK, T. AYGÜN}

birkaç verim yönlü kayıtları tutmaktadır (Turan 2004; Tuna 2005). Yapılan inceleme ve araştırmalar neticesinde yazılımların büyük çoğunluğu ise büyükbaş hayvanlarda süt verimini tutmak, hesaplamak ya da buna göre bir yetiştiricilik yapma eğiliminde olan yazılımlardır.

Bu program, araştırma ve yetiştirme çiftlikleri için;

- Tutulan kayıt türü sayısı,

Kullanım amacı, kolaylığı ve dili

- Veri filtreleme mantığ1,

Verileri yazdırma/aktarmadaki yöntemi

- Tek ekrandan birçok veriye ulaşım,

- Birçok alana hitap etmesi,

- Formül, yöntem bilmeye gerek kalmadan otomatik olarak hesaplama, sonuç görme,

- Veri türü alternatiflerini bulundurması,
- Islah ve seleksiyon çalışmalarında yardımcı kayıtları bulundurması,

- Tüm Windows sistemlerinde çalışması,

- Bakım, onarım masrafi gerektirmemesi,

- Şifreli giriş ve verilen yetkiler ile programın korunmas1,

- Veritabanının taşınabilmesi kolaylığı,

- Veri girildikçe sonuç gösteren yapısı,

- Veri hırsızlıklarına karşı koruma,

gibi birçok durum bakımından dünyada ilk çalışma özelliğindedir (Çelikyürek ve Aygün 2015). Program ileriki çalışmalarda daha da zenginleştirilerek ilaveler ile hayvan yetiştirme, ıslah çalışmalarında vazgeçilmez bir yazılım durumuna getirilecektir. Yazılan bu program tutulan kayıt sayısı ve çalışma alanlarının büyük bir kısmını kapsaması bakımından da önemli bir yere sahiptir. Sürü bazında gerekli temel bilgileri vermesinin yanında akademik çalışmalarda da kullanılabilecek kayıtları tutması bakımından önemli bir çalışmadır. İleride yapılacak çalışmalara da 1şık tutması beklenmektedir.

\section{Teşekkür}

Bu makale, birinci yazarın doktora tez çalışmasının bir bölümünden derlenmiştir.

\section{Kaynaklar}

Akdağ F (2004). Yerli ırk mandalarda kesim yaşının kesim ve karkas özellikleri üzerine etkisi. İstanbul Üniv. Vet. Fak. Derg. 30(2): 79-86.

Alpan O (1993). Sığır yetiştiriciliği ve besiciliği. Ankara Üniversitesi, Veteriner Fakültesi, Zootekni Anabilim Dalı, 3. Basım, 320s, Ankara.

Altuğ N, Özdemir R, Cantekin Z (2013). Ruminantlarda koruyucu hekimlik: 1. Aşı Uygulamaları. Erciyes Üniversitesi, Veteriner Fakültesi Dergisi 10(1): 33-44.

Anonim (2014). Salmonellosis. İbrahim Çetin. http://balikesir.tarim.gov.tr/Belgeler/ Forms/AllItems.aspx?RootFolder=\%2fBelgeler\%2fPPT\&FolderCTID=0x012000BBFA0B2672 B65A4B8A84E781B025FF75. Erişim Tarihi: 06.09.2014.

Anonim (2016). Siğırlardan alınan ölçüler ve ölçme. Serap GÖNCÜ, http://www.muratgorgulu.com.tr/altekran.asp?id=11, Erişim Tarihi: 09.12.2016.

Aydın İ, Günlü A (2010). Hayvancılık işletmelerinde teknik ve finansal verilerin tutulmasına ve değerlendirilmesine yönelik bir bilgisayar yazılımı. Vet. Hek. Dern. Derg. 80(4): 21-30.

Aytekin İ, Kalınbacak A, İşler CT (2011). Ruminantlarda kullanılan aşılar ve önemi. YYÜ Vet. Fak. Derg. 22(1): 59-64.

Aytuğ CN, Alacam E, Görgül S (1989). Sığır Hastalıkları. Tüm-Vet Hayvan. Hiz. Yayını. Tekno Grafik. İstanbul. 655s.

Ceyhan A, Erdoğan İ, Sezenler T (2007). Gen kaynağı olarak korunan Kıvırcık, Gökçeada ve Sakız koyun ırklarının bazı verim özellikleri Tekirdağ Ziraat Fakültesi Dergisi 4(2): 211-218.

Cloete JJE, Hoffman LC, Cloete SWP Fourie JE (2004). A comparison between the body composition, carcass characteristics and retail cuts of South African Mutton Merino and Dormer sheep. South African Journal of Animal Science 34(1): 44-51.

Çelikyürek H, Aygün T (2014). Küçükbaş ve büyükbaş hayvancılıkta kayıt tutmanın önemi ve güncel yazılımların uygulanabilirliği. IMAC 2014, Uluslararası Mezopotamya Tarım ve Hayvancılık Kongresi, 22-25 Eylül 2014. Diyarbakır, Türkiye.

Çelikyürek H, Aygün T (2015). Küçükbaş Hayvancılıkta Kayıt Tutma Sistemine Yönelik Bir Bilgisayar Paket Programının Hazırlanması. UZBK2015, 9. Ulusal Zootekni Bilim Kongresi, 3-5 Eylül 2015, (Sözlü Bildiri, Tam Metin), s:158-165, Konya.

Dolgun MÖ, Özdemir TG, Oğuz D (2009). Veri madenciliğinde yapısal olmayan verinin analizi: Metin ve web madenciliği. İstatistikçiler Dergisi 2: 48-58. 
Ekiz B, Özcan M, Yılmaz A, Koçak, Ö, Ergul Ekiz E, Yalçıntan H (2012). Sütten kesim yaşının Kıvırcık kuzularda sütten kesim stresi, büyüme, karkas ve et kalitesi özellikleri üzerine etkileri. İstanbul Üniversitesi Araştırma Fonu Projesi, Kesin Rapor, Proje No: 5442, 7 İstanbul. 84s.

Ertuğrul M, Dellal G, Cedden F, Akman N, Yener M, Türkoğlu M, Elibol O, Firatlı Ç, Gençer HF (2011). Hayvan Yetiştirme. Anadolu Üni. Yayın No: 2255, AÖF Yayın No: 1252, Eskişehir. 247s.

FAO (2014). Commission on genetic resources for food and agriculture. intergovernmental technical working group on animal genetic resources for food and agriculture. Draft Guidelines for the Development of Integrated Multipurpose Animal Recording Systems. Eighth Session, 26-28 November 2014, Rome. 175p.

García-Segovia P, Andrés-Bello A, Martínez-Monzó J (2007). Effect of cooking method on mechanical properties, color and structure of beef muscle (M. pectoralis). J. of Food Eng. 80(3): 813-821.

Gaytancıoğlu O (2008). Türkiye hayvancılığının günümüzdeki durumu ve sorunları. Dünya Gıda Dergisi, Mart Sayisi.

Gökçen H (2015). Hayvancılıkta kayı tutmanın önemi. http://www.hazimgokcen.net/ hayvancilik/hayvancilikta-kayit-tutmanin-onemi/. Erişim Tarihi: 23.02.2015.

Gökdal Ö, Aygün T, Bingöl M, Karakuş F (2003). The effects of docking on fattening performance and carcass characteristics of male Karakaş lambs. South African J. of Animal Sci. 33(3): 185-192.

Güney O, Ocak S (2010). Entansif besi koşullarında Boer x Balcalı Melezi (BBLC) ve Balcalı (BLC) erkek oğlakların besi performansı ve karkas özellikleri üzerinde bir araştırma. Ulusal Keçicilik Kongresi 24-26 Haziran 2010, Çanakkale. s: 391-397.

Insausti K, Beriain MJ, Purroy A, Alberti P, Lizaso L, Hernandez B (1999). Colour stability of beef from different Spanish native cattle breeds stored under vacuum and modifed atmosphere. Meat Science 53: 241-249.

Jones SM (1995). Quality and Grading of Carcasses of Meat Animals. CRC Press, ISBN: 0-8493-50239, Printed in the United Stattes of America. 240.

Karaca O, Cemal İ, Yılmaz O. (2012). Halk elinde hayvan ıslahı ülkesel projeleri. Tarımsal Araştırmalar ve Politikalar Genel Müdürlüğü (TAGEM), Aydın-Denizli-Uşak (Adu) Alt Projeleri Çalıştay Notları. 21.09.2012, Aydın.

Kaymakçı M (2013). İleri Koyun Yetiştiriciliği. (Genişletilmiş 4. Bask1), Mayıs 2013, İzmir. 336s.

Kaymakçı M, Sönmez R (1992). Koyun Yetiştiriciliği. Hasad Yayıncılık, Hayvancılık Serisi 3, Eylül 1992, İstanbul. 405s.

Kulaksız R, Daşkın A, Dalcı T (2011). Aşım sezonunda farklı ırk koyunlarda flugeston asetat-ecg ile östrus senkronizasyonu sonrası bazı reprodüktif özellikler. Ata. Üni. Vet. Bil. Derg. 6(1): 9-15.

Kumlu S (1999a). Sığır yetiştiriciliğinde neden kayıt tutulmalı. Damızlık Sığır Yetiştiricileri Dergisi, Setma Matbaacilık, 15 Haziran 1999. s: 10-11.

Kumlu S (1999b). Damızlık ve Kasaplık Sığır Yetiştirme. Setma Matbaacılık, Isbn:975-96864-0-6, Antalya, 166s.

McGee M, Keane MG, Neilan R, Moloney AP, Caffrey PJ (2007). Body and carcass measurements, carcass conformation and tissue distribution of high dairy genetic merit Holstein, standard dairy genetic merit Friesian and Charolais x Holstein-Friesian male cattle. Irish Journal of Agricultural and Food Research 46: 129-147.

Özhan M, Tüzemen N, Yanar M (2011). Büyükbaş Hayvan Yetiştirme. Atatürk Üniversitesi Ziraat Fakültesi Ders Notu, Yayın No :134, Erzurum.

Öztürk Y, Odabaşığlu F (2011). Van ve yöresinde Hamdani koyunlarının verimleri ve morfolojik özelliklerinin araştırılması: II. Kuzularda büyüme, yaşama gücü, besi performansı kesim ve karkas özellikleri. Yüzüncü Yıl Üniversitesi Veteriner Fakültesi Dergisi 22(2): 81-87.

Sekin S, Voyvoda H, Ağaoğlu Z, Karaca M (1996). Yüzüncü Yıl Üniversitesi Veteriner Fakültesi İç Hastalıklar Kliniğine Van ve çevresinden 1992 -1997 yılları arası getirilen hayvanlarda saptanan hastalıkların genel analizi. Yüzüncü Yıl Üniversitesi Vet. Fak. Derg. 7(1-2): 106-109.

Şahin EH, Akmaz A (2004). Koyunlarda süt verim özellikleri ve kontrolü. Vet. Bil. Derg., 20(1): 5-11.

Tuna H (2005). Büyükbaş hayvanların zeki RF kartlarla internet üzerinden kimliklendirilmesi. Gazi Üniversitesi, Fen Bilimleri Enstitüsü, Yüksek Lisans Tezi, Ankara.

Turan T (2004). Sığırlarda kayıt tutulmasını sağlayan bir bilgisayar programının hazırlanması. Yüzüncü Yıl Üniversitesi, Fen Bilimleri Enstitüsü, Zootekni Anabilim Dalı, Yüksek Lisans Tezi, Van.

Yakan A (2012). Koyun ve keçilerde süt verim kontrol yöntemleri ve laktasyon süt veriminin hesaplanmasi. AVKAE Dergisi 2: 18-23.

Yaralı E, Karaca O (2011). Farklı besi sistemlerinde besiye alınan Karya kuzularda besi performans1, kesim ve karkas özellikleri. Hayvansal Üretim 52(2): 1-9. 